\title{
PLAYFUL PARTNERSHIPS FOR GAME-BASED LEARNING IN INTERNATIONAL CONTEXTS
}

\author{
Jeremiah H. Kalir - University of Colorado Denver \\ Michael Fahy - University of Michigan \\ Jeff Kupperman - University of Michigan-Flint \\ Farrah M. Schiff - University of Michigan \\ Jeff Stanzler - University of Michigan
}

This book chapter to appear in I. Lubin (Ed.), ICT-supported innovations in small countries and developing regions: Perspectives and recommendations for international education. New York, NY: Springer.

Do not quote without author permission.

Questions concerning this manuscript should be addressed to:

Jeremiah H. Kalir

Assistant Professor, Information and Learning Technologies

School of Education and Human Development

University of Colorado Denver

1380 Lawrence St., Room 645

Denver, CO 80204

remi.kalir@ucdenver.edu

Office: (303) 315-0034

Fax: (303) 315-6311

\begin{abstract}
This chapter examines the playful design and enactment of games for learning, and details generative and provocative attributes of playful multistakeholder partnerships for information and communications technologysupported game-based learning in international contexts. Drawing upon the experiences of two educational technology research and development groups, the chapter first identifies four design principles that have guided various global - and playful - game-based learning partnerships in Jamaica, Oman, South Africa, and Switzerland. Such international partnerships were designed as opportunities to co-construct game-based learning by articulating the permitted, establishing collaborative presence, attending carefully to trust, and fostering third space. The second half of this chapter features a case study of ICT-supported game-based learning in Oman, and describes different ways in which a playful multistakeholder partnership can be enacted in a cross-cultural setting. The subject of this case study is Place Out of Time (POOT), a trans-historical simulation of a trial in which students play guests who come from a range of places and time throughout history to discuss some of the great issues of humankind, and to bring the wisdom of history to a modern-day problem. Utilizing narrative methods, four vignettes from playing POOT in Oman are presented that convey the complex, and sometimes contradictory characteristics of playful partnerships for game-based learning in a developing region. The chapter concludes by arguing for a more critical playfulness in game-based learning that can support all partners and players in confronting biases, celebrating difference, and creatively addressing local and global needs.
\end{abstract}

Key words: design narrative, design principles, game-based learning, Oman, partnerships, play 


\title{
Chapter 7
}

\section{PLAYFUL PARTNERSHIPS FOR GAME-BASED LEARNING IN INTERNATIONAL CONTEXTS}

\author{
Jeremiah H. Kalir - University of Colorado Denver \\ Michael Fahy - University of Michigan \\ Jeff Kupperman - University of Michigan-Flint \\ Farrah M. Schiff - University of Michigan \\ Jeff Stanzler - University of Michigan
}

Abstract: This chapter examines the playful design and enactment of games for learning, and details generative and provocative attributes of playful multistakeholder partnerships for information and communications technologysupported game-based learning in international contexts. Drawing upon the experiences of two educational technology research and design groups, the chapter first identifies four design principles that have guided various global - and playful - game-based learning partnerships in Jamaica, Oman, South Africa, and Switzerland. Such international partnerships were designed as opportunities to co-construct game-based learning by articulating the permitted, establishing collaborative presence, attending carefully to trust, and fostering third space. The second half of this chapter features a case study of ICT-supported game-based learning in Oman, and describes different ways in which a playful multistakeholder partnership can be enacted in a cross-cultural setting. The subject of this case study is Place Out Of Time (POOT), a trans-historical simulation of a trial in which students play guests who come from a range of places and time throughout history to discuss some of the great issues of humankind, and to bring the wisdom of history to a modern-day problem. Utilizing narrative methods, four vignettes from playing POOT in Oman are presented that convey the complex, and sometimes contradictory characteristics of playful partnerships for game-based learning in a developing region. The chapter concludes by arguing for a more critical playfulness in game-based learning that can support all partners and players in confronting biases, celebrating difference, and creatively addressing local and global needs.

Keywords: design narrative, design principles, game-based learning, Oman, partnerships, play

\section{INTRODUCTION}

The spread of information and communications technology (ICT) to improve educational opportunity in small countries and developing regions must be accompanied by an invigorated focus that simultaneously introduces and supports innovative pedagogies and social practices. Such an approach recognizes the fluid socio technical landscape of technology use in developing nations (de Laet \& Mol, 2000), and also honors complex relations among social, material, cultural, and historic influences that shape the use of learning technologies for more equitable educational futures (Facer, 2011; Johri, 2011). We contend that a sociotechnical stance is necessary given international educational development efforts which tend to foreground the primacy of tools over associated practices. Despite well-intentioned concern for a global digital divide and the inequitable distribution of educational resources, focusing foremost on access to particular tools may inadvertently ignore the promise of local social and cultural practice (and may, in 
fact, exacerbate entrenched inequality). Because such a dynamic may be pronounced in small and developing regions, we argue that a coupling of technological and sociocultural practices can create conditions that are more favorable for innovative pedagogical approaches conducive to 21 st century learning. In this respect, our chapter intentionally balances attention to a given technology (digital games) and related social practices (those of game play). Moreover, we advocate that it is precisely because of complex relations among culture, power, and authority that sociotechnical practices associated with play are a promising approach to educational development work in small countries and development regions.

Play is strongly associated with both formal and informal learning, as evidenced by connections among play and language development, socialization, problem solving, cultural identity, and creative expression (Edwards, 2000; Kangas, 2010; Lemke, Lecusay, Cole, \& Michalchik, 2015; Paley, 1992; Smith, 2010). Play is also closely coupled to ICT given advances in digital games and game-based learning (Gee, 2007; Salen, 2008; Salen Tekinbas, Gresalfi, Peppler, \& Santo, 2014; Squire, 2011; Steinkuehler, Squire, \& Barab, 2012). There are distinct affordances and limitations when coupling together play, digital media, and game-based learning, particularly when including diverse stakeholders in the co-design of ICT and related learning opportunities (e.g. Salen Tekinbas, 2014; Squire, 2010; Williams-Pierce, 2016). Digital game play has been found to support a range of learning practices and outcomes as afforded by ICT, from inquiry and motivation to assessment and achievement (Barab, Gresalfi, \& Ingram-Goble, 2010; Fishman, Riconscente, Snider, Tsai, \& Plass, 2014; Wouters \& Oostendorp, 2013; Young et al., 2012).

Given the scope of this volume and focus of our research, we are concerned with the adoption of digital game-based learning in international contexts and developing regions (e.g. Hwang \& Wu, 2012; Schmitz, Felicia, \& Bignami, 2015). More specifically, the proliferation of such media practice has both expressly and inadvertently positioned digital games as an example of ICT for development (ICTD). For example, Brewer and colleagues (2005) suggest that games may be a culturally appropriate means of multimedia storytelling for children in rural and low-income schooling contexts. Within content-specific domains like literacy and mathematics, researchers in India have successfully supported youth English-language learning in out-of-school contexts (Kam, Kumar, Jain, Mathur, \& Canny, 2009) and have also reinforced mathematics skills through remedial education (Banerjee, Cole, Duflo, \& Linden, 2007). In light of such efforts, it may not be surprising that Patra, Pal, and Nedevschi's (2009) ICTD state of the union reported that over a quarter of surveyed ICTD experts ranked games as an area of future importance in education.

Yet in spite of a small and notable research strand that has explored the role of (digital) games in social and economic development activities, Fisher (2016a) cautions that it "remains unclear whether games present a radically new approach to development, or simply a new technological platform for replicating traditional projects" (p. 33). As for games presenting a novel form of social and economic ICTD, Kolko and Putnam (2009) suggest games and gaming culture may be harnessed as one aspect of a broad ICT ecology that "diffuses throughout and affects nascent computer users in developing regions" (p. 47), such as in Central Asia. In this regard, games are perceived as a favorable first touch and entry point for the diffusion of ICT given low barriers to access, high motivation, and everyday relevance. Alternatively, research by Kam and colleagues (2008) represents the latter perspective, whereby carefully iterated digital games are deployed as a means to support traditional literacy and language learning objectives among rural children in India (see also Pal, Pawar, Brewer, \& Toyama, 2006). Evidence suggests digital games are often used simply to replicate conventional ICTD, bolstering Fisher's (2016b) complementary criticism of gamification efforts as yet another iteration of technological dominance favoring capitalist development goals. When game design and play are co-opted for explicitly productive and commercially fruitful non-game contexts, games may be critiqued for continuing a lineage of mass communication technologies that exacerbate power disparities and advance neoliberal agendas in the international development industry (Arora, 2012).

While digital games can be researched and critiqued as a tool instrumental in either transcending or (more likely) reinforcing traditional development activities, a handful of researchers have advocated an alternative focus on the promise of play in ICTD. Chirumamilla and Pal (2013) argue that an affective, open-ended, and idiosyncratic perspective on play within ICTD can create an opportunity "through which 
the constraining, infantilizing rhetoric of the developmental optic may be broken" (p. 31). Advocating ludic design, or the importance of non-productive fun, Chirumamilla and Pal describe playfulness in three ICTD cases from rural India: Namma Dhwani (Our Voices), a community-based radio programming effort that subverted commercial broadcasting regulations to better address local needs and interests; Digital Green, a series of agricultural training videos that discarded prescriptive tutorials from outside experts in favor of everyday scenarios with "people who looked like them [farmers], wearing similar clothes, talking in dialects and with mannerisms relatively similar to their own" (p. 29); and MILLEE (Mobile and Immersive Learning for Literacy in Emerging Economies), a game-based approach to literacy learning that foregrounded youth's everyday context and cultural practices throughout all stages of the game design process. With similar sympathy to postcolonial criticism, Ferreira (2015) centers play not as an entertaining mechanism for greater development productivity, but rather because of the deliberative and constructive potential of play to advance freedom in ICTD.

As a point of contrast to primarily capitalist endeavors, Fisher (2016a) has advanced a model of Critical Play due to the tendency for digital games to be used in international development contexts for expressly commercial causes. Such play arises through digital games "that address structural inequality as the root cause of underdevelopment and ask players to engage in critique and conceptualize solutions outside of the current system... to challenge local and global power structures through gameplay and educate players about systemic issues that exacerbate development issues" (p. 34). The research presented in this chapter aligns well with such critical perspectives on digital games and play in developing contexts, as we consider play a disruptive break in the normative state of affairs that can serve as a means "to shock, alarm, and challenge conventions" (Sicart, 2014, p. 15) in the design and enactment of ICT-supported game-based learning.

\subsection{Game-based learning and play in Oman}

Our goal in this chapter is to detail the generative and provocative attributes of play and playful multistakeholder partnerships when facilitating game-based learning in the context of Oman, and to consider the broader potential of such partnerships on educational practices in small developing regions. As notions and typologies of development have come under critical review in recent years (Escobar, 2008; Sachs, 2010), Oman provides an interesting counter-example to entrenched notions of a so-called developing nation - as well as the extent to which an ICT-supported educational partnership, such as the case described here, might flourish in such a context. Despite being one of the poorer Arab states in the Persian Gulf, Oman's GDP has grown continuously in the last 50 years alongside large-scale investment in national infrastructure and economic liberalization. Notably, some of the country's largest budgetary outlays have been in basic education. Oman's commitment to reducing oil dependence while increasing economic diversification has given greater urgency to the adoption of innovative education approaches as a means of preparing the next generation of Omani students for 21 st century careers. In spite of such development, perception - from a Western perspective - of Oman's tendency toward autocratic reform may suggest little opportunity, whether practically or politically, for more playful approaches to educational practices. Whether in an Omani or Western context, it is fair to question how games and play complement (or contradict) more conventional education systems and prescriptive learning routines. Nonetheless, the case presented in this chapter indicates Omani students and educational organizations can be supportive of ICT-supported game-based learning, and that such playfulness aligns with broader narratives about the country's ongoing commitments to development, education, and innovation.

We write as researchers, teacher educators, and designers affiliated with two game-based learning research and design groups located at the University of Michigan: the Interactive Communications and Simulations Group (ICS; http://ics.soe.umich.edu), and the Institute for Innovation in Education (iiE; http://iie.icsmich.org). Founded in the late 1970s, ICS designs and supports an assortment of web-based learning technologies for primary, secondary, and higher education students and their teachers, with the goal of promoting creative expression, cultural inquiry, and civic engagement. Having engaged over 400 
primary and secondary schools in 36 American states and 25 countries (some of which may be described as developing nations, such as Brazil, Bulgaria, Morocco, Oman, Russia, Tanzania, and South Africa), as well as dozens of higher education partners, the ICS portfolio of web-based ICT include games, simulations, and online social networks concerned with various interdisciplinary topics, such as conflict in the Middle East, cross-cultural exploration and exchange, trans-historical role-play, immersive narratives, public policy debate and development, and poetry. Research about students' ICS participation suggests these projects strengthen skills such as argumentation, perspective-taking, and literacy development, while also promoting more playful orientations toward traditional schooling (D'Angelo \& Kline, 2012; Holden, Stanzler, Fahy, \& Kupperman, 2015; Kupperman et al., 2011; Kupperman, Stanzler, Fahy, \& Hapgood, 2007). Furthermore, educator participation in ICS projects has been shown to aid pedagogical decisionmaking, reflection upon students' socio-cognitive engagement, and the development of mentoring capabilities (deNoyelles \& Raider-Roth, 2015; Killham, Tyler, Venable, \& Raider-Roth, 2014). The ICS project featured in this chapter - Place Out Of Time (POOT) - exemplifies many characteristics of (digital) games that can foster player's identity experimentation, pro-social collaboration, and civic engagement across diverse settings and cultural contexts (e.g. Gee, 2007; Salen, 2008; Squire, 2011).

After over three decades designing game-based ICT, ICS affiliates created a new organizational mechanism to further bolster the social, cultural, and global connections necessary to enact such innovative media, practices, and learning. In 2012, the Institute for Innovation in Education established a global network of designers, educators, and researchers so as to rethink and redesign learning environments and experiences, bridge a gap between academic and popular culture, and broker social and civic engagement among K-12, higher education, and workplace learning. The iiE built upon the success of nascent global partnerships and game-based learning strategies incorporated into an educational technology graduate program facilitated by ICS researchers and teacher educators (Holden, 2013). From its inception, a hallmark of iiE programming has been an ongoing series of Gatherings - events planned collaboratively with international partners, hosted at schools and universities across the globe, and facilitated with the goal of exchanging ideas and co-constructing innovations for more equitable and participatory learning. To date, Gatherings have occurred in Switzerland, South Africa, the Czech Republic, Canada, and annually in the United States; complementary work under the iiE umbrella has engaged stakeholders from schools, universities, government, non-profit organizations, and the private sector in Jamaica, Japan, and Oman.

This chapter draws upon our ICS and iiE experiences designing and playing games with a host of global partners and describes, in particular, distinct opportunities and challenges associated with one playful multistakeholder partnership in the developing international context of Oman. ICS and iiE aim to advance ICT-supported game-based and playful learning in developing regions as a response to the fact that partnership trust, collaboration, and innovation are historically and systematically less commonplace in such contexts (e.g. Borland, 2014). As such, we address two questions in this chapter: First, what design principles guide our co-creation of playful game-based learning partnerships? And second, how is a playful partnership enacted when these principles inform game-based learning in developing regions?

\section{DESIGN PRINCIPLES FOR PLAYFUL PARTNERSHIPS}

Our work with ICS and iiE is as much about creating games for learning as it is about fostering playful educational partnerships. What do we mean by playful, particularly as educational partnerships are seldom cultivated or described as playful? Following Sicart (2014), we appreciate that being playful requires appropriating a context not expressly designed for play and that "playfulness glues together an ecology of playthings, situations, behaviors, and people, extending play toward an attitude for being in the world" (p. 25). In this section, we share four design principles that guide how we glue together an ecology - that is, how we create the conditions - for playful partnerships given varied ICT, social practices, and cultural diversity. Heeding Hoadley and Cox's (2009) observation that "identifying a single, reliable method for 
learning technology design amounts to a futile search for the Holy Grail" (p. 21), we articulate some principles for playful partnership, rather than definitive prescriptions for material objects or technical processes. These principles are neither a linear and exhaustive method, nor are they abstract propositions. To avoid such interpretation, we highlight extensively our prior work in various international and gamebased learning contexts as evidence of how specific design principles were developed and have evolved. In doing so, we acknowledge that our design principles may be particularly well-suited to the unique challenges and opportunities associated with ICT-supported learning in developing regions (see Lubin, this volume). We then follow this section with a case study of ICT-supported game-based learning in Oman - a learning context, we will argue, that remains in a state of development - illlustrating holistically and in detail how our design principles can be enacted, at other times contested, and can lead to expressions of play, partnership, and critical playfulness.

\subsection{Articulating the permitted}

Consistent with user-centered design processes that welcome a plurality of contributions during ideation and iteration (e.g. Brown, 2008), we approach game-based learning partnerships by articulating what is permitted. Among our influences as designers are (digital) games in which players' decisions are constrained by a basic premise - certain actions are required, some forbidden, and then others are permitted (e.g. Allen, Jackson, Ross, \& White, 1978). We adapt this particular game mechanic as a design principle. It is the permitted - that which represents possibility and the manifold potential of play as free movement within structure (Salen \& Zimmerman, 2004) - that serves as a root metaphor when we cultivate partnerships for game-based learning, particularly with partners from varied cultures, contexts, and geographies.

We neither demand, for example, that a partner purchase proprietary software as a requirement, nor do we prohibit focusing upon a partner's local curricular needs; that is, we do not emphasize our agenda while rendering theirs forbidden. We contend this is a particularly salient approach in developing regions, where resources may be scarce and where there is often "uncritical international transfer of educational policy and practice from one context to another" (Crossley \& Watson, 2009, p. 636). Rather, we articulate what is permitted, such as how (digital) game play might honor players' cultures and interests (e.g. Peppler \& Kafai, 2010), encourage expressions of empathy (e.g. Bachen, Hernandez-Ramos, \& Raphael, 2012), or embrace the ambiguity inherent to play (Sicart, 2014). When, for example, we designed DevInfo GameWorks (DIGW), an online platform that supported players' creation and exchange of games about international development data, our partnership with the Community Systems Foundation was more launchpad than contract. That relationship brokered subsequent game-based learning collaborations in developing regions - such as a partnership with UNICEF and the Jamaican Ministry of Education, and also with primary schools in South Africa - all of which were intended to meet local education needs:

When DIGW was first proposed, the immediate goal was to increase awareness of global issues in general and the Millennium Development Goals in particular. An early pilot with urban sixth grade students established that DIGW can be an effective tool for this aim. Since then, however, the system has been used to achieve a wide variety of different content goals: for example, a primary school teacher in South Africa was attracted by the opportunity for learners to practice English language expression in an authentic environment; a college professor used it to help her students learn literacy education concepts; and a high school journalism teacher saw it as a way for her students to do grass-roots journalism. (Kupperman et al., 2010, p. 297) 
By articulating the permitted, we privilege a more expansive approach to the co-construction of novel practices and ways of knowing, rather than market a rigid and often arbitrary codification of what counts as game-based learning and how people should (and should not) play among diverse cultural contexts.

\subsection{Establishing collaborative presence}

As a complement to articulating the permitted, we contend that the successful design of playful partnerships also requires establishing collaborative presence. Presence is a complex and contested notion, with social and spatial dimensions (e.g. Aragon, 2010), pedagogical implications (e.g. Anderson \& Dron, 2010), and varied methodological interpretations (e.g. Slater, 1999). Our approach to presence is, first and foremost, embodied. While many of our games utilize dedicated ICT, such as websites and online social networks, our partnerships are enacted through physical and material dimensions. Prior to play, we traverse oceans, exchange gifts, and participate in everyday rituals that broker familiarity and trust in a participatory community (Lave \& Wenger, 1991). Such activities demonstrate why presence is particularly important when enacting collaborative ICT-supported learning in developing regions (e.g. David, Rega, Vannini, \& Cantoni, 2013). Though we appreciate how ICT can afford greater access and availability in an increasingly connected world, we believe that playing together means being beside one another in-game and in-room (Stevens, Satwicz, \& McCarthy, 2008).

Beginning in 2007, we started experimenting with collaborative presence and agile partnership models through our facilitation of an educational technology graduate program located in Geneva, Switzerland. Our approach to the design of graduate education echoed our design of games for learning. Whether with game play or cross-cultural partnership, synchronous presence in shared space and time can deepen qualities of collaboration and make learning relevant to local needs and interests (e.g. Barron, Gomez, Pinkard, \& Martin, 2014; Gutiérrez \& Penuel, 2014). Many of our graduate students were classroom teachers who, collectively, called nine countries home; accordingly, their collaborative presence in the creation of learning technologies included:

[working] with the world's leading fair labor watchdog to design and implement an online economic justice simulation for high school students. Websites and curricular resources about human rights in China, community gardening in Michigan, environmental conservation in Mexico, and global citizenship in the Congo were presented to - and then critiqued by - an official from the UN's International Labor Organization... [Another] team built solar photovoltaic systems, developed a curriculum to address barriers to rural electrification, and handed the hardware and digital resources to a South African mobile learning organization. (Holden, 2013, p. 5)

Collaborative presence, in our experience, often includes listening attentively, identifying and mitigating bias, and honoring in-the-moment improvisations characteristic of game-based learning (e.g. Holden et al., 2014). Establishing collaborative presence is not the achieved win-state of a single game. Rather, presence in a playful partnership invariably fluctuates, with collaboration demanding ongoing negotiation among the values, practices, and objectives of all partners - a necessary, yet challenging, premise when partnering in developing contexts. 


\subsection{Attending to trust}

Like collaborative presence, trust in educational partnerships is neither a given nor an outcome established via formulaic procedure. Rather, attending to trust is a process of attunement whereby familiarity grows among stakeholders' cultures, norms, and expectations (e.g. López Turley \& Stevens, 2015). In our work, trust is a social practice that recurrently attends to boundaries and boundary crossing. A boundary may demarcate disciplinary expertise, or suggest sameness, highlight sociocultural difference, or define what "counts as... central participation" (Akkerman \& Bakker, 2011, p. 132). Boundary crossing, therefore, can refer to practices and dynamics that (re)design and (re)conceptualize learning across intercultural contexts (e.g. Resta \& Laferrière, 2015), as well as among multiple perspectives and partners, demonstrating "ways in which sociocultural differences and resulting discontinuities in action and interaction can come to function as resources for learning and development of intersecting identities and practices" (Kumpulanein \& Sefton-Green, 2014, p. 13). Trust in partnerships entails recognizing and respecting boundaries, from the ritual of cultural tradition, to insight from personal experience, to the constraints of a game as designed learning experience.

Yet attending to trust in a playful partnership also honors - and actively encourages - boundary crossing. Recall that play may be understood as both free movement within structure and also a transgression of norm or expectation. When, for instance, learners in developing nations like Jamaica and South Africa designed DIGW games, our game-based learning partnerships required trust when honoring spatial, technical, and conceptual boundary crossing (Kupperman et al., 2010). Together, children, adults, and researchers attended to the joint work of game design as movement among people and places, data, and ideas about community and identity:

In contrast to the schools we worked with in South Africa, where the learners ventured out into the community to gather material for their games, the learners in Kingston used information they could gather from the computer lab, much of it using DevInfo software to access data about Jamaica. We expected this to be challenging, and it was, especially considering that DevInfo is a sophisticated tool used mostly (until now) by governments and UN agencies, and the learners are just completing grade six... The questions the kids came up with were important and real: Is crime in Jamaica increasing or decreasing? How much poverty is there here compared to other countries? Is there a difference between how girls and boys are doing in school? The conclusions they came to were not always what they expected at first, and with some guidance, they were able to form their findings into a game that is quite accurate, and yet entirely their own. (Kupperman, 2010, para. 3)

Whether in data analysis or game design, boundary crossing promotes different perspectives on shared activity and contributes to the co-construction of novel practices. Because play is transgressive and also transformative, we attend to trust in our game-based learning partnerships by creating the conditions for continuous joint work at and across boundaries.

\section{$2.4 \quad$ Fostering third space}

The final principle that guides our approach to playful game-based learning partnerships is fostering third space. With a rich conceptual lineage (e.g. Bhabha, 1994; Soja 1996) and transformative enactment in educational research (e.g. Gutiérrez, 2008; Moje et al. 2004), varied definitions of third space broadly refer to the emergence of new perspectives, narratives, and practices - and for both individuals and groups 
- that result from hybrid discourses and spaces. Our commitment to fostering third space reflects the consequences of boundary crossing: "Given a certain problem space, practices that are able to cross their boundaries engage in a creative process in which something hybrid - that is, a new cultural form emerges" (Akkerman \& Bakker, 2011, p. 148). Because ICS games (like DIGW) and iiE efforts (like playful partnerships) span both developing and developed international contexts, we contend that initiatives like ICT-supported game-based learning are well-suited to foster hybrid and emergent learning:

This may be the most important reason for games to be part of school. Games provide students the opportunity to break with common sense and yet be taken seriously in the context of the game, even though everyone knows that outside the game what they are doing might be absurd. Games provide us an opportunity to take our students' explorations seriously, without being judgmental or condescending. They provide safe bubbles where students (and teachers) can take risks and try out different ways of thinking, inviting others to attend to their actions while preserving a distinction between their own self and the role they have taken on. These actions are worthy of our attention because they will show whether players have been able to take the leap to a different way of thinking. If our job is to facilitate, then it is not so much to help the players understand where they have arrived as to help them understand where they have been. (Kupperman et al., 2011, p. 29)

Our approach to game-based learning partnerships in both developing (i.e. Jamaica, Oman, South Africa) and developed (i.e. Japan, Switzerland) countries eschews so-called best practices in global ICT efforts (e.g. Zhang, Yang, Chang, \& Chang, 2016) that may too readily average Western perspectives with the diverse cultures of stakeholders in such contexts. On the contrary, we are cognizant that fostering third space is suitable - if not increasingly necessary - so as to advance innovative ICT partnerships in developing contexts that are divorced from a history of distrust and the interventionist diffusions of topdown reform (David, Sabiescu, \& Cantoni, 2013). Our shared partnering seeks to evince something entirely distinct. What we describe as a playful partnership necessarily draws upon, and yet simultaneously seeks to transcend, the dominance and bias of any one culture or way of knowing. We maintain that playfulness through games can foster - given participatory design, trust, and collaborative partnering $-\mathrm{a}$ third space for nascent and transformative learning.

\section{A PLAYFUL PARTNERSHIP FOR GAME-BASED LEARNING}

Having identified design principles for playful game-based learning partnerships, we now present a case study that describes different ways in which a playful partnership may be enacted in a cross-cultural and developing nation context. This case features the ICS game Place Out Of Time (POOT), a trans-historical simulation of a trial in which students play guests who come from a range of places and time throughout history to discuss some of the great issues of humankind (i.e. justice, identity), and to bring the wisdom of history to a modern-day problem (i.e. religious liberty). To do so, students role-play - online and inperson - historical and contemporary characters (e.g. Queen Isabella, Gandhi), and discuss cultural, social, and moral issues in those characters' voices. We loosely employ the motif of a trial to animate players' POOT interactions, usually designating a handful of characters as justices, who solicit support from other guests, and in the end formally issue their opinion on a case. The process creates ample room for discussion and politicking, and in so doing, students have a contextually-rich opportunity to practice historical research, deliberation, and perspective-taking (Kupperman et al., 2007). We also want students to embrace theatrical attitudes when playing POOT, such that their social interaction - primarily via online writing - is imbued with the voice of their character, and the tone they imagine their character 
might take (Kupperman et al., 2011). Figure 1 below is a screenshot from the POOT website that supported role-play and debate in our featured case.

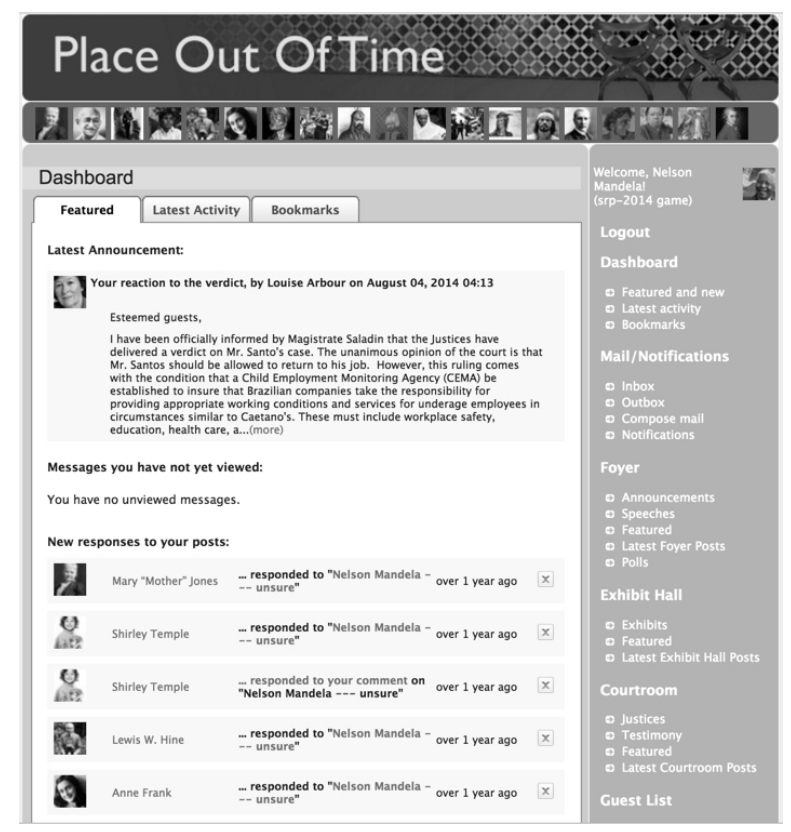

Figure 1. POOT website that supported Omani game-based learning partnership

\subsection{Establishing POOT in Oman}

In 2014, after over a dozen years orchestrating imaginary encounters among diverse historical and social perspectives, we found ourselves in a real-life meeting of cultures. Representing ICS and iiE, we were invited to design and facilitate a version of POOT for a group of secondary students in Oman. These students were participants in a summer residential program (SRP) organized by the Takatuf Scholars Programme. Takatuf is a social responsibility initiative of the Oman Oil Company, the nationalized oil enterprise of the Sultanate of Oman, and one manifestation of decades-long Omani educational reform (e.g. Al Balushi \& Griffiths, 2013). Each year, a cohort of 80 Grade 11 Takatuf Scholars participate in academic and extracurricular programming. Through a competitive evaluation process, ten Scholars from among this group are awarded full scholarships to both an international preparatory school and then a four-year university in the United States, Canada, or the United Kingdom. Scholars attend the SRP for three weeks to commence their Takatuf experience. POOT's digital game-based learning and communication-intensive qualities appealed to our partners as a novel means of initiating the SRP in alignment with Oman's broader education reform efforts.

Briefly, education in modern Oman has undergone dramatic transformation across elementary, secondary, and higher education systems (Alfar, 2013; Hussain \& Al Barwani, 2015) that reflect the country's overall "growth miracles" (United Nations Development Programme, 2010, p. 3). Until 1970, there were all of three schools with a modern curriculum in the entire country, with a total enrollment of 900 pupils (A1 Balushi \& Griffiths, 2013). Following the accession to power of Sultan Qaboos in 1970 and a series of educational reforms, that figure rapidly expanded; by 2010, over 520,000 students were enrolled in 1,040 schools. All Omani children have access to a free education through the end of the secondary level. While school is not mandatory at any level, more than 90 per cent of school-aged 
children are enrolled, with girls represented proportionately to their general population demographics. Since the 1990s, and so as to prepare "young Omanis for life and work under the new conditions created by the global economy" (ibid, p. 155), the Ministry of Education has introduced comprehensive reforms designed to prepare Omani students for a globalized knowledge economy, placing emphasis on learnercentered education, the acquisition of communication and learning skills, and the development of critical thinking (see also United Nations Development Programme, 2010).

It is within this educational reform context that our game-based learning partnership with Takatuf sought to further their goal of providing "secondary school students with the practical and intellectual tools needed to support their success not only as university students, but also as lifelong learners and future leaders." In addition to Takatuf, our prior work with Omanis and extensive international contacts allowed us to establish a network of stakeholders from multiple sectors to meaningfully enact POOT in Oman. Our multistakeholder partnership included: Takatuf's directors and staff; the Sultan Qaboos Cultural Center; a member of the Diwan, Oman's Royal Court; a representative from the International Labour Organization in Geneva, Switzerland; and a financial analyst from the Central Bank of Oman, who first became acquainted with ICS games as an undergraduate student at the University of Michigan.

A playful attitude among the many stakeholders of our partnership was necessary given a number of constraints unique to the Omani version of POOT. First, the usual online model of POOT spans eight weeks; this version would need to conclude in three days. Second, when POOT is facilitated online, we rely on classroom teacher-partners to support students as they research and become their characters; in Oman, we would need to more concretely support this process ourselves, building on work begun during the spring by Takatuf staff, and taken on individually by the Scholars in the intervening weeks. Third, the 80 participating Scholars were paired to play shared characters. Among the 40 shared characters were those reflecting cultural traditions and histories more familiar to Omani students (e.g. Ibn Rushd), as well as contemporary figures known for more controversial, if not explicitly Islamophobic, opinions (e.g. Marine le Pen). Fourth, though we drafted a scenario about migrant labor in Oman, playing with the volatility of regional politics was simply too risky. Accordingly, the game's central trial concerned child labor and leveraged residual excitement from the 2014 FIFA World Cup that had recently concluded in Brazil to focus upon that country's child labor issues. The scenario concerned Caetano Santos, a fictional Brazilian teenager who worked in a clothing factory until fired following an investigation into illegal child labor. Caetano - proud of contributing to his family's wellbeing - sought a ruling from the POOT Court of All Time that would allow him and other minors to return to work.

Given the unique contingencies of implementing POOT in Oman, we were purposeful about the use of ICT by Scholars, Takatuf and SRP staff, and our facilitation team. For example, each Scholar had access to a laptop computer. As such, they were able to research their characters online and practice speaking as their characters in written peer-to-peer interactions on the POOT website. Via these online forums, Scholars could also communicate directly with Caetano, played by a member of our team based in the United States. Throughout the game, we also presented a series of mock newscasts (Figure 2 below) that provided important information about child labor in Brazil and gave Caetano a face (i.e. stock image) and voice (via internet translating services). Scholars were further immersed in the game's scenario as Takatuf staff role-played reporters and recorded video interviews of Scholars while they were in-character. Finally, we utilized video conferencing technology so that Scholars, while role-playing, could speak with an international labor expert in Geneva, Switzerland.

\footnotetext{
${ }^{1}$ For additional information about the Takatuf Scholars Programme see www takatufscholars.com.
} 


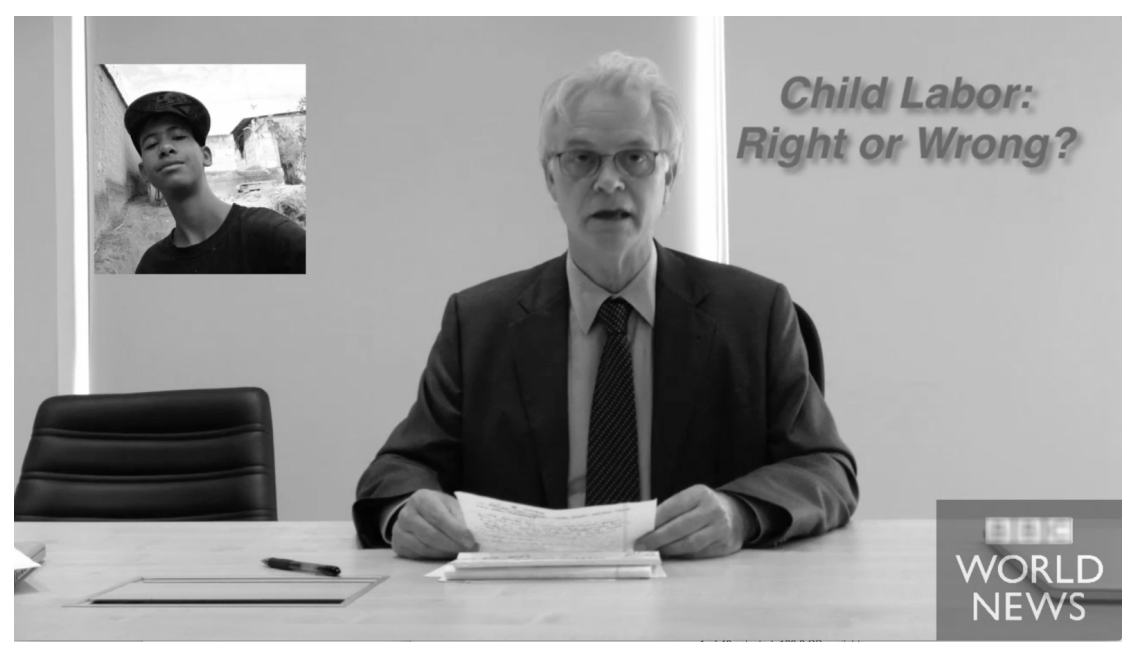

Figure 2. A mock newscast that playfully introduced the Omani POOT scenario

The following vignettes provide additional glimpses of our playful, multistakeholder partnering in the creation, facilitation, and reflection upon POOT in Oman. Influenced by narrative inquiry (Clandinin, 2006) and design narrative (Bell, Hoadley, \& Linn, 2004) methods, these four vignettes deliberately play with voice (both ours as researchers, and also those of participating Takatuf Scholars), style, and structure. We contend this approach more authentically represents the complex - and sometimes contradictory characteristics of playful partnerships for ICT-supported game-based learning in international contexts.

\subsection{Vignette 1: Introductory quote cards}

Nine o'clock on a sweltering August morning. Thirty minutes into our first day of POOT Oman and everything looks fairly traditional. Our team of four facilitators stands at the front of a classroom. We introduce ourselves and POOT to 80 Takatuf Scholars - young women seated to our right, young men to our left - listening attentively. Atop their desks is a numbered card. For our first activity, we explain, everyone will stand, move about, and find three peers with the same numbered card. Having formed a group of four, they will flip over their cards, read a quote, and collectively interpret its meaning. But first we do something quite bizarre. We four go to different corners of the room, then begin wandering about, each waving a card numbered 21 . We quickly gather together. One of us reads aloud: "I am a citizen of the world." We pause, then ask: "What does that mean?" More silence. Another one of us asks, "Well, what does citizen mean?" Collectively, publicly, we analyze our quote, each offering a new interpretation. The Scholars quietly observe our modeling, their faces excited and a bit puzzled.

And then, "Go!" The invisible line separating male and female disappears as Scholars whiz past each other, stopping only to compare cards, group, or move on (Figure 3 below). 


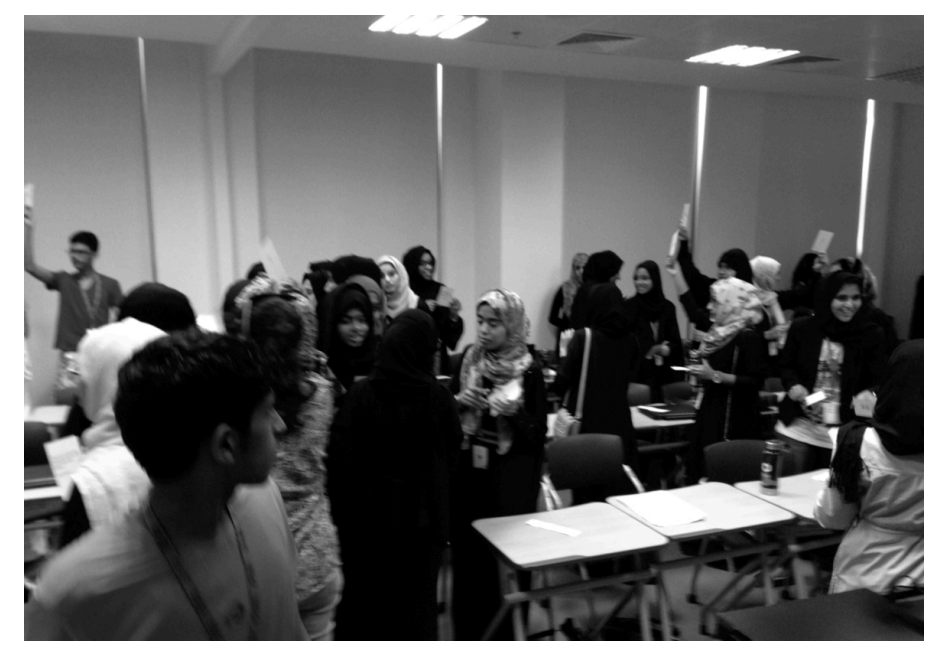

Figure 3. Takatuf Scholars form groups during introductory Quote Cards activity

The groups of Scholars assemble - some unisex, some mixed - and clump together around the room, at desks, and in the hallway. They speak loudly. Dozens of excited voices exchange ideas for fifteen minutes. We facilitators then gather five Quote Card groups together and find space where each can summarize their discussion and present interpretations. Some groups do not reach a consensus, offering multiple meanings of a quote. Some have their interpretation challenged by peers. Most Scholars are eager to speak. The twenty-minute debrief stretches to forty. One group, for example, interprets "It is the first responsibility of every citizen to question authority," from Benjamin Franklin, to mean citizens should try to understand or have a dialog with authority, rather than to challenge authority. Given our Western biases, the Scholars' interpretations often challenge our perspectives and contradict our expectations.

The reflection ends, the Scholars take a break, and we debrief. We are in awe. The Scholars' eagerness to participate is noteworthy given what we ultimately learn about their day-to-day education. For a majority of the 80 Scholars, the SRP is their first mixed-gender learning opportunity. Others would also tell us how their schools follow a direct instruction model, within which they obediently listen, take notes, and do not participate in such spontaneous and open-ended discourse. Their typical schooling stands in stark contrast to the Quote Cards activity. We are also aware that the Scholars' variable English proficiency did not limit collaborative participation. Our Takatuf partners had requested a languageintensive introduction to POOT's terminology. Yet rather than study vocabulary out of context, we chose to plunge the Scholars into a playful examination of quotations, shifting the activity from definition to interpretation. The Scholars' willingness to play along is that much more impressive.

\subsection{Vignette 2: Misreading signs}

In this version of POOT, the game's scenario features the plight of Caetano Santos, a Brazilian teenager who worked in a clothing factory until fired following an investigation into illegal child labor. Caetano proud of contributing to his family's wellbeing - seeks reemployment and brings his case before the Court of All Time. While fictitious, our POOT scenarios and trials are always based upon real world concerns. In Brazil, anyone younger than 16 is not permitted to work, yet apprenticeship laws and inconsistent compliance practices present persistent challenges; over one million boys and girls, aged 5 to 14 years, work illegally in Brazil (Bureau of International Labor Affairs, 2014). Lending further credibility to the POOT scenario, we arrange a video conference so that the Takatuf Scholars can discuss - while roleplaying as their characters - questions about child labor, employment, and economic security with a policy 
analyst at the International Labour Organization in Geneva, Switzerland. As with many well-intentioned designs, however, we confront an unanticipated challenge.

Our conversation is organized for the second morning of the SRP, less than 24 hours after we begin playing POOT. All 80 Scholars sit together in our shared classroom, young women on the left, young men on the right. At the front of the room we arrange desks and computers to facilitate our video conference, and invite Scholars to sit before their peers, pose questions to our guest expert, and publicly discuss child labor (Figure 4 below). Something, however, is amiss.

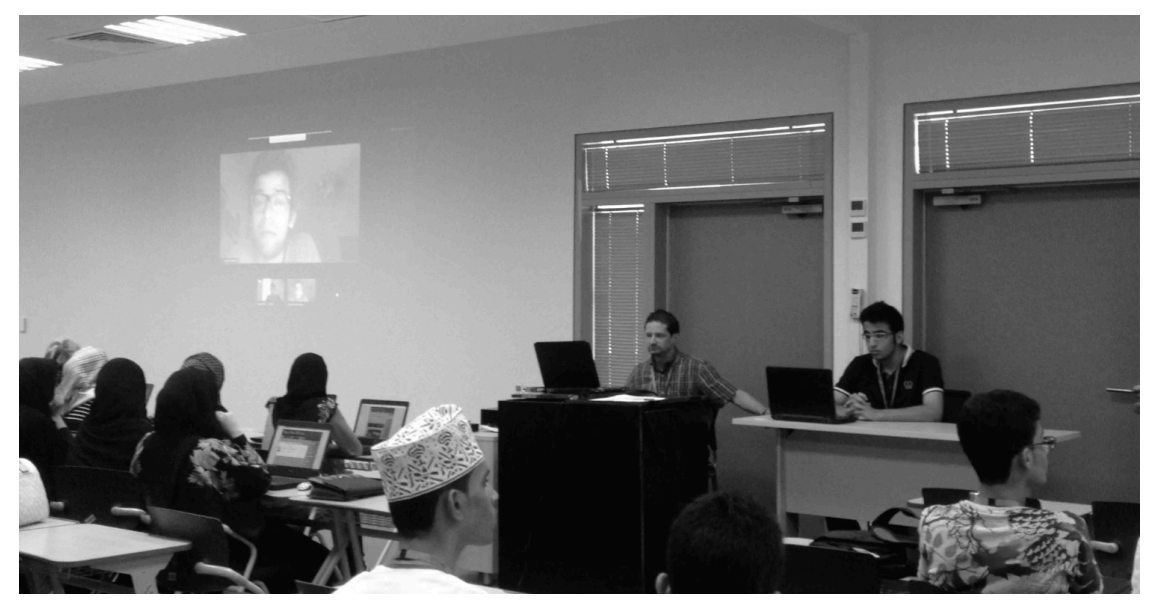

Figure 4. A Takatuf Scholar discussing child labor with ILO economic policy analyst

During our first day together, the Scholars confidently adapted to the playfulness of POOT and enthusiastically embraced their character role-play. While we recognize the unique mixed-gender arrangements of the SRP, the Scholars readily interacted in this atypical learning environment. Perhaps mistakenly, we begin to question our own assumptions about norms associated with education, gender, and social interaction. As the conversation linking Muscat and Geneva commences, first one male Scholar, then another, and a third sit to ask a question. We quickly realize that young men are entirely comfortable role-playing in this particular physical arrangement, and in social interaction with an expert male stranger. Alternatively, not a single female Scholar is willing to leave her seat and enter what is - as readily becomes clear - a highly gendered space. With this realization, we immediately adjust our facilitation by circulating a microphone to female Scholars so that they are welcomed into the conversation. Only then does our activity proceed more equitably and with greater Scholar participation.

\subsection{Vignette 3: Be(com)ing Mother Jones}

With thick, plastic-rimmed white glasses and Elvis-inspired hair, Zarif ${ }^{2}$ looks like someone who can push a few boundaries. He is unhappy role-playing a woman, particularly someone with whom he is entirely unfamiliar - the American labor organizer Mary "Mother" Jones. In typical versions of POOT, young women frequently role-play male characters, while young men rarely choose to play female characters. In Oman, strong social norms determine where and how males and females can gather together. As such, we - navigating our own roles as outsiders - do not risk assigning female characters to the male Scholars. We work carefully with our Takatuf partners to finalize an appropriate list of 40 historic and contemporary characters who can debate the game's child labor scenario. Ultimately, the characters are assigned to

\footnotetext{
${ }^{2}$ Zarif is a pseudonym.
} 
Scholars by Takatuf's staff. Hence, Zarif - in sideburns and his grey dishdasha robe - is challenged to become Mother Jones. And over the course of only a few days, Zarif-as-Mother Jones capably testifies during POOT's final trial. Speaking to a panel of three adults role-playing the trial's justices, Zarif confidently remarks as Mother Jones: "In my days, I encountered many factories that hired children to work, and I succeeded in opposing most of them... With my great experience and knowledge in these factories, I'm sure that such factories are dangerous and unsuitable for children to work at."

What allowed Zarif to convincingly role-play Mother Jones - whether with fellow Scholars face-toface, in written online exchange, and before a panel of highly esteemed adults? And what compelled Zarif - more than two weeks after the game ended - to continue speaking as Mother Jones in response to Gandhi (Figure 5 below)?

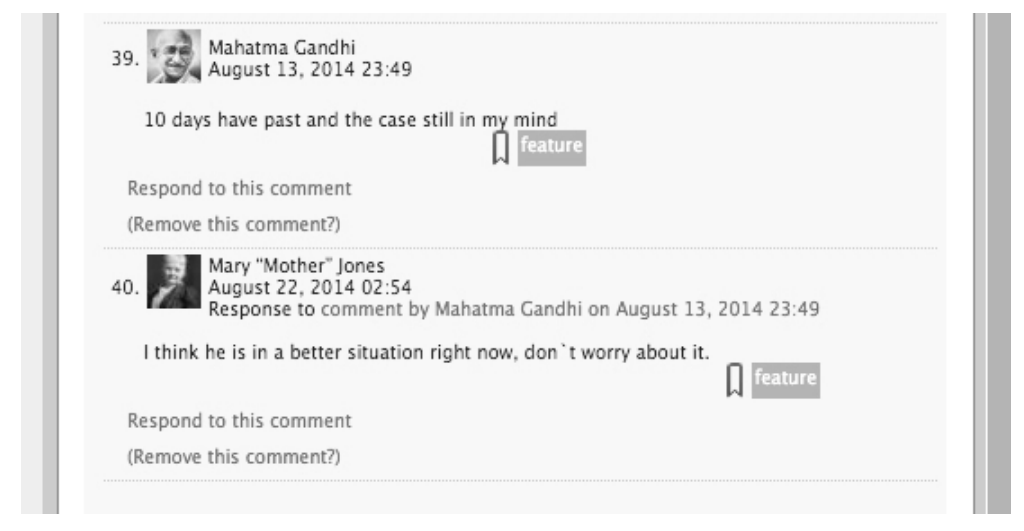

Figure 5. Mother Jones' comment to Gandhi more than two weeks after POOT concluded

In a debrief, Zarif told us that despite his preconceptions, when researching Mother Jones he learned of someone who was feisty, strong, and independent-minded. Indeed, she was the kind of person he aspired to become in his life. Even more surprisingly, Zarif discovered that his own father knew of Mother Jones and was a lifelong admirer. These conditions may not entirely explain how Zarif role-played someone of a different age, culture, and gender, someone who had different life experiences and who was not afraid to challenge authority. For a young man in Oman to act similarly in everyday circumstances could have notable consequences. However, the playful constraints of POOT suspended certain cultural norms, allowing players' actions to carry new and different meanings. POOT encouraged Zarif, like other Takatuf Scholars, to play with the rules governing social interaction: "So when I came here, at first, I thought 'How am I going to do this?' But actually, it was very easy for me. I don't know how, but I actually got into my character so much that when I'm talking from Mother Jones' perspective, I forget myself!"

\subsection{Vignette 4: A trial, and a verdict?}

I am Louisa May Alcott, from United States. I was a novelist and social worker. I do support Caetano's request. When I was a child, the poverty made it necessary to work... We need to live in a world that all people have decent, happy lives... Would someone prefer to work and live a decent life, or read a book with an empty stomach in a place just like that [Scholar points to image of poverty, Figure 6 below]? This would be Caetano's situation if he doesn't get a job. 


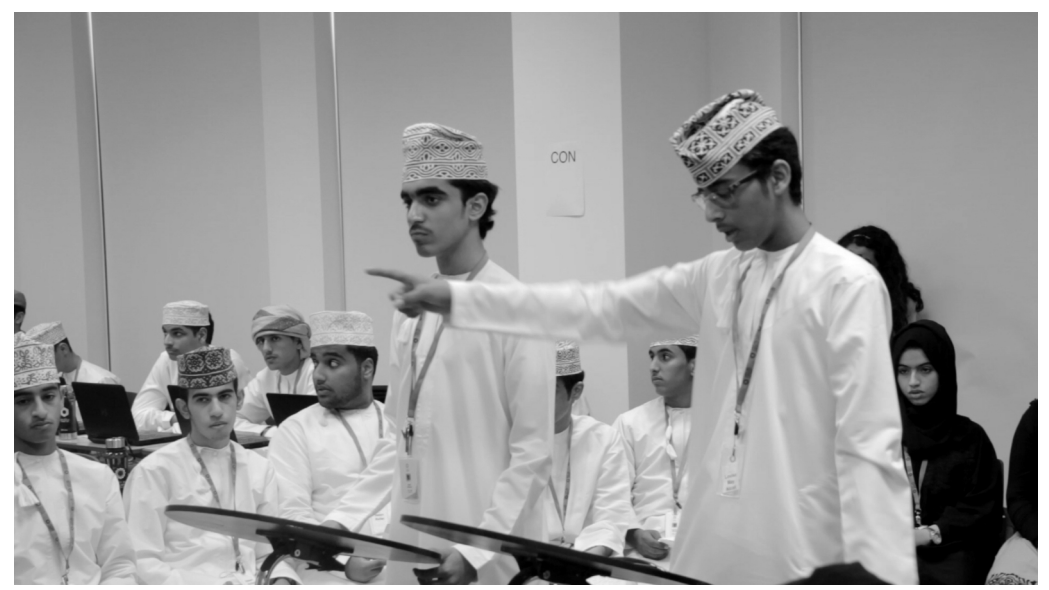

Figure 6. Takatuf Scholars roleplaying Louisa May Alcott testify during trial

With 80 Scholars in the same place at the same time, we amplified dramatic aspects of the game's final trial that are not possible in the larger, exclusively online version. Each pair of Scholars would jointly present their character's stance on Caetano's case, arguing in response to key questions that had guided our research and preparation. Are human rights best served if children are protected from working before they reach adulthood? Should human rights be defined as protecting the rights of young people to make their own decisions about whether or not to work? Furthermore, testimony would occur before three adults role-playing as Justices: a member of the Diwan (Oman's Royal Court); our former student, now an analyst at the Central Bank of Oman; and the Programme Director of Takatuf. Would this Court of All Time judge Caetano based upon economics, morality, safety, or individual liberty?

When we asked Takatuf's Programme Director to serve as a Justice she readily agreed. On the final morning of POOT, shortly before Scholars began testifying, she hastily informed us that the Justices would not render a "yea or nay" verdict about Caetano's fictitious case. The Programme Director, herself a North American, strongly opposed any definitive outcome. Confused, we inquired about her rationale. She was not worried about the Scholars' debate or competitiveness. Rather, Scholars could plausibly regard a verdict enjoined by a member of Oman's Diwan as a formally sanctioned truth. Moreover, a Scholar's argumentative stance - even one presented during role-play - could be construed as undermining the authority of a government official, leading to potentially inappropriate or shameful outcomes. Despite having explained role-play responsibilities, and having secured these leaders' eager cooperation as Justices, it appeared that our effort to simulate a more realistic trial with support from respected representatives of Oman's civil society was forbidden. Ambiguity and conflict notwithstanding, we played on. Scholars' testimony (Figure 7 below) alternated between characters favoring Caetano's right to work and those arguing for his protection as a minor.

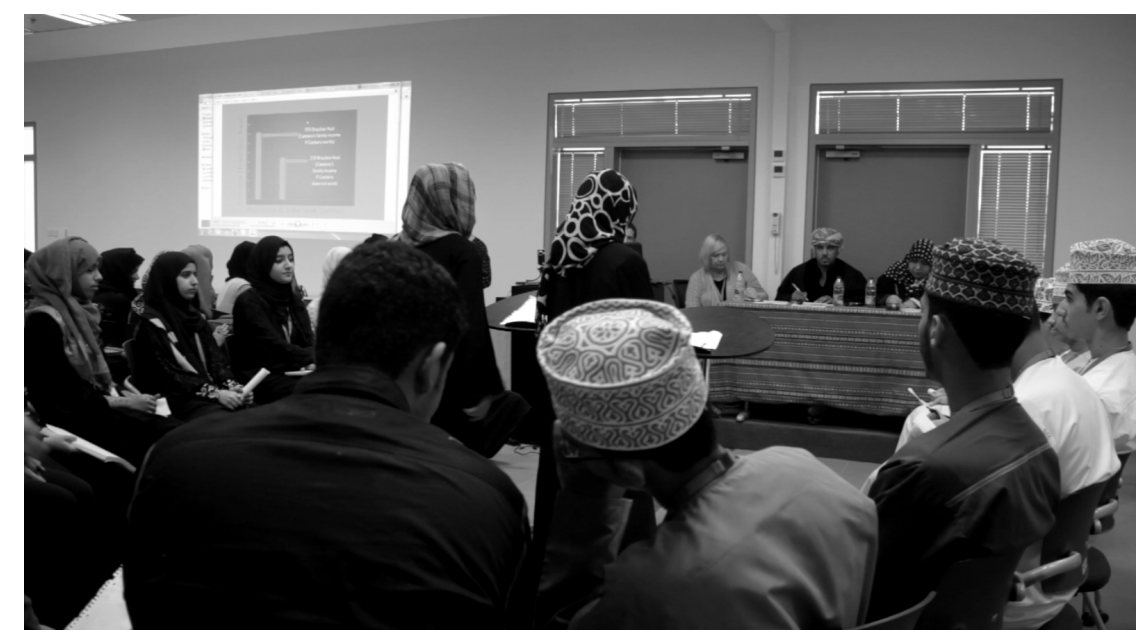


Figure 7. Takatuf Scholars roleplaying Ellen Johnson Sirleaf testify before Justices

As is evident in the exchange below, the justices routinely engaged the Scholars in thoughtful and respectful deliberation.

Nelson Mandela: I'm not saying that children should not work in factories or in a safer place. I'm saying children must not work at all. The government must provide them with support, like money, food, and shelter, so that they don't have to work until they are the proper age. Let's say the government provides Caetano's family with money. He wouldn't have to work. In fact, he would go to a school and he would educate himself so that, in ten years from now, he will have made an income for himself.

Justice: We make the assumption that the government has unlimited resources. As someone that studies economics, that's not actually a fact. So when you always say, 'The government should, the government should, the government should,' we anticipate that the government has endless funds. But in some countries, the governments don't. And in those countries, the government cannot facilitate completely - or for all the children - what you're requesting. Then what do you suggest in this case?

Nelson Mandela: Well, I'm saying, the country we're talking about right now is Brazil. Brazil has so much poverty. And during 2014, Brazil has spent over two billion dollars on the World Cup, right? Those two billion dollars they could have put toward fixing poverty, schools inside the country. Yes, they have limited resources, but they do have resources they could have put in education.

The Scholar's nuanced analysis, character-appropriate perspective taking, and in-the-moment improvisation was impressive. Yet throughout the testimony, we worried about how the Justice's decision could avoid conflict and - what we believed would become - a dramatic anticlimax. Our uncertainty only deepened as the Justices retreated to a separate classroom for their own deliberation. And then, quite unexpectedly, they returned with a verdict. A unanimous decision determined that Caetano would return to his job at the clothing factory. The Justices presented the verdict, accompanied by the Scholars' shock and excitement; the result was also posted in detail to the game's online platform (Figure 8 below).

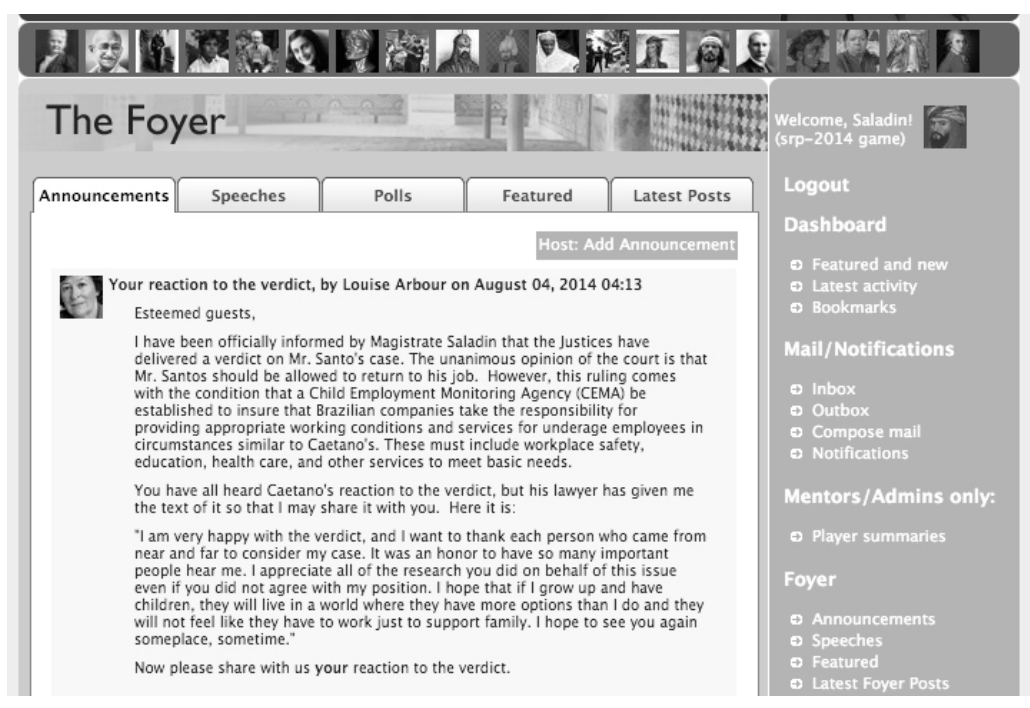


Figure 8. The trial verdict posted online

We will never know what prompted the Justices to agree - unanimously - upon their verdict. Perhaps the momentum of the trial dictated this discrete outcome. Perhaps Scholars' role-play and passionate testimony rendered the verdict ancillary to their more impressive demonstration of competence and creativity. Or maybe the in-character interactions between Scholars and Justices were the truly significant occurrence. There was, we believe, an appropriate and playful ambiguity to the game's conclusion.

\section{TOWARD CRITICAL PLAYFULNESS IN GAME-BASED LEARNING}

We have described how international partnerships generally and, more specifically, multistakeholder collaboration in developing regions can be an opportunity for co-constructing activities of critical playfulness (i.e. Ferreira, 2015; Fisher, 2016a) based upon principles of articulating what is permitted, establishing presence, attending carefully to trust, and fostering a third space in which game-based and playful activity occurs. This playful approach to educational partnerships means that learning outcomes may not be completely known in advance, and this in turn makes it possible to take thoughtful risks, critique decision-making, and make necessary adjustments on the fly. Whereas some (digital) game-based learning delimits stakeholder agency for the sake of control and measurement (Holden, 2016), we advocate - on the contrary - that critical playfulness can be a generative, at times uncomfortable or unanticipated, and transformative approach to ICTD in small countries and developing regions.

The multistakeholder partnership that supported POOT in Oman, like our broader and ongoing ICS and iiE efforts, allowed critical playfulness to co-opt what very easily could have been a learning environment more akin to traditional school. In these ways, we suggest our approach to game-based partnering contributes to the social production of "openings in time and space where play becomes possible. The contexts in which playfulness happens are not designed or created for play: they are occupied by play" (Sicart, 2014, p. 28). In the case of POOT in Oman, expressions of playfulness momentarily occupied the Takatuf SRP, leading one Scholar to reflect, "As I was a government school student, I would have really loved and appreciated it if someone provided me with this way of learning." As a challenge to dominant conventions of both schooling and ICTD - and whether in developing contexts like Oman, the United States (where, it may be argued, many public school systems are similar to those in developing nations), or elsewhere - playful game-based learning partnerships can engender hybrid spaces whereby all partners, irrespective of age and status, may speak differently, playact, critique, and design new ways of learning.

Given the distinct qualities of our playful multistakeholder partnerships, it is reasonable to anticipate questions about implementation, impact, and sustainability. What happens if such partnerships are not advanced? How might individuals and organizations appreciate the impact and meaning of critical playful learning? And are such playful partnerships sustainable given more traditional approaches to schooling and learning? As designers and researchers of learning technologies - and not, for that matter, experts in comparative education or conventional international education development - we suggest such questions are best addressed by further amplifying the voices of our partners. We contend it is important to advance such partnerships because of learners who, after only a few days playing POOT, noted: "The main thing I learnt is that we shouldn't just look at one perspective. In fact, if we take everyone's opinion we might end up with a solution to a problem that everyone is happy with. This event has also given me multiple skills like teamwork, listening, decision making and how to put myself in others' shoes." Moreover, in the view of Scholars, such partnerships should be sustained as complementary to current educational practice: "I think this event should be applied in school at least once a week every two months or so. It gives students so many skills that they will be able to use in the future; be it at school, university, work or even dealing with people everyday." 
Because we are designers and educators who regularly traffic along and across boundaries, we remain ever-curious - if not also skeptical - about the types of impact and meaning-making that accompany ICTD and ICT-supported game-based learning. We certainly appreciate the Takatuf Scholar who remarked, "I learned so many things such as how to see things from another person's perspective, embrace and accept other people's personalities." Yet we cannot simply congratulate ourselves on a game well played. Indeed, many other game-based learning opportunities scaffold players' perspective-taking (e.g. Steinkuehler et al., 2012) or promote distinctive partnerships (e.g. Salen Tekinbas et al., 2014). Accordingly, we contend that cross-cultural and multistakeholder play - rife with excitement, miscommunication, and surprise - may serve more complex and expressly critical purposes. In this respect, we recognize how "games serve as tools to make privileges, positions, and points of view visible" (Souto-Manning, 2010, p. 999). Furthermore, we admire Flanagan's (2009) orientation to critical play as gameplay "characterized by a careful examination of social, cultural, political, or even personal themes that function as alternates to popular play spaces" (p. 6). These perspectives are both rare and necessary particularly in ICTD contexts - given how game play so easily traverses fluid and expansive social networks. So too are these perspectives indispensable if game-based learning is to more meaningfully help players and learners from around the world confront biases, celebrate difference, and creatively address local and global needs.

We will always carry our Western positions and personalities into international game-based learning partnerships. As such, our design principles for playful partnerships and our commitment to critical playfulness must serve multiple ends for all stakeholders: establish a shared educational endeavor through collaboration and mutual respect; create the conditions for participatory and more equitable game play; and support players' critique of social, cultural, and historical perspectives. Moreover, both our design principles and game-based learning opportunities must also function as a cohesive set of strategies for mitigating the harmful effects of unquestioned power, privilege, and global inequality. Playing POOT in Oman, we learned that boundaries are not always clearly marked (including our own), that signs can be both poorly designed and misread, and that at times certain assumptions need not be discarded but rather carefully refined. Wherever gameplay takes ICS and iiE - across geographies, concepts, and cultures - we recurrently affirm that a particular type of critical and playful agility is something we seek to cultivate in learners, in partners, and in ourselves.

\section{ACKNOWLEDGEMENTS}

We thank the many students, classroom teachers, and education leaders on five continents who have participated in ICS and iiE games and programming over the past 30 years. We are particularly grateful to the students and staff of the Takatuf Scholars Programme, as well as our other colleagues in Oman, without whom the playful partnership described in this chapter would not have been possible. Lastly, we thank Fred Goodman, whose work continues to be the foundation - and an inspiration - for all that we do.

\section{REFERENCES}

Akkerman, S. F., \& Bakker, A. (2011). Boundary crossing and boundary objects. Review of Educational Research, 81(2), 132169.

Al Balushi, S., \& Griffiths, D. (2013). The school education system in the Sultanate of Oman. In G. Donn \& Y. Al Manthri (Eds.), Education in the broader Middle East: Borrowing a baroque arsenal (107-126). Oxford, United Kingdom: Symposium Books Ltd.

Alfar, E. (2013). Oman. In D. Ness \& C-L. Lin (Eds.), International education: An encyclopedia of contemporary issues and systems (pp. 657-659). New York, NY: Routledge. 
Allen, E., Jackson, G., Ross, J., \& White, S. (1978). What counts is how the game is scored: One way to increase achievement in learning mathematics. Simulation \& Games, 9(4), 371-392.

Anderson, T., \& Dron, J. (2010). Three generations of distance education pedagogy. The International Review of Research in Open and Distributed Learning, 12(3), 80-97.

Aragon, S. R. (2010). Creating social presence in online environments. In S. R. Aragon (Ed.), New directions for adult and continuing education (57-68). San Francisco, CA: Jossey Bass.

Arora, P. (2012). The leisure divide: Can the 'Third World' come out to play? Information Development, 28(2), 93-101.

Bachen, C. M., Hernández-Ramos, P. F., \& Raphael, C. (2012). Simulating REAL LIVES: Promoting global empathy and interest in learning through simulation games. Simulation \& Gaming, 43(4), 437-460.

Banerjee, A. V., Cole, S., Duflo, E., \& Linden, L. (2007). Remedying education: Evidence from two randomized experiments in India. The Quarterly Journal of Economics, 122(3), 1235-1264.

Barab, S. A., Gresalfi, M., \& Ingram-Goble, A. (2010). Transformational play using games to position person, content, and context. Educational Researcher, 39(7), 525-536.

Barron, B., Gomez, K., Pinkard, N., \& Martin, C. K. (2014). The Digital Youth Network: Cultivating new media citizenship in urban communities. Cambridge, MA: The MIT Press.

Bell, P., Hoadley, C. M., \& Linn, M. C., (2004). Design-based research in education. In M. C. Linn, E. A. Davis, \& P. Bell (Eds.), Internet environments for science education (pp. 73-85). Malwah, NJ: Lawrence Erlbaum Associates.

Bhabha, H. (1994). The location of culture. London, UK: Routledge.

Borland, R. (2014). The PlayPump. In S. Walz \& S. Deterding (Eds.), The gameful world: Approaches, issues, applications (pp. 323-338). Cambridge, MA: MIT Press.

Brewer, E., Demmer, M., Du, B., Ho, M., Kam, M., Nedevschi, S., ... \& Fall, K. (2005). The case for technology in developing regions. Computer, 38(6), 25-38.

Brown, T. (2008). Design thinking. Harvard Business Review, 86(6), 84-92.

Bureau of International Labor Affairs. (2014). Brazil: 2014 findings on the worst forms of child labor. Washington, D.C.: United States Department of Labor.

Chirumamilla, P., \& Pal, J. (2013, December). Play and power: a ludic design proposal for ICTD. In Proceedings of the Sixth International Conference on Information and Communication Technologies and Development: Full Papers-Volume 1 (pp. 25-33). ACM.

Clandinin, D. J. (Ed.). (2006). Handbook of narrative inquiry: Mapping a methodology. Thousand Oaks, CA: Sage Publications.

Crossley, M., \& Watson, K. (2009). Comparative and international education: Policy transfer, context sensitivity and professional development. Oxford Review of Education, 35(5), 633-649.

D’Angelo, J., \& Kline, S. L. (2012). Argumentative discourse skill development in online educational simulations: How George Carlin can teach critical thinking. Paper presented at the American Educational Research Association Annual Meeting, Vancouver, B.C.

David, S., Sabiescu, A., \& Cantoni, L. (2013, November). Co-design with communities. A reflection on the literature. In J. Steyn \& A.G. Van der Vyver (eds.), Proceedings of the 7th International Development Informatics Association Conference (IDIA) (pp. 152-166).

deNoyelles, A., \& Raider-Roth, M. (2015). Being an 'agent provocateur': Utilising online spaces for teacher professional development in virtual simulation games. Technology, Pedagogy and Education, 25(3), 337-353.

de Laet, M., \& Mol, A. (2000). The Zimbabwe bush pump: Mechanics of a fluid technology. Social Studies of Science, 30(2), $225-263$.

Edwards, C. P. (2000). Children's play in cross-cultural perspective: A new look at the Six Cultures study. Cross-cultural Research, 34(4), 318-338.

Escobar, A. (2008). Territories of difference: Place, movements, life, redes. Durham, NC: Duke University Press.

Facer, K. (2011). Learning futures: Education, technology, and social change. New York, NY: Routledge.

Fisher, J. (2016a). Toward a political economic framework for analyzing Digital Development Games: A case study of three games for Africa. Communication, Culture \& Critique, 9(1), 30-48.

Fisher, J. (2016b). Digital development and international aid: Are games changing the world? In H. Gangadharbatla \& D. Davis (Eds.), Emerging Research and Trends in Gamification (pp. 276-303). Hershey, PA: IGI Global.

Fishman, B., Riconscente, M., Snider, R., Tsai, T., \& Plass, J. (2014). Empowering educators: Supporting student progress in the classroom with digital games. Ann Arbor, MI: University of Michigan.

Flanagan, M. (2009). Critical play: Radical game design. Cambridge, MA: The MIT Press.

Ferreira, P. (2015). Play as Freedom: Implications for ICT4D (Doctoral dissertation, KTH Royal Institute of Technology). 
Gee, J. P. (2007). What video games have to teach us about learning and literacy. New York, NY: Palgrave Macmillan. Gutiérrez, K. D. (2008). Developing sociocultural literacy in the third space. Reading Research Quarterly, 43(2), $148-164$. Gutiérrez, K. D., \& Penuel, W. R. (2014). Relevance to practice as a criterion for rigor. Educational Researcher, 43(1), $19-23$. Hoadley, C., \& Cox, C. (2009). What is design knowledge and how do we teach it? In C. DiGiano, S. Goldman, \& M. Chorost (Eds.), Educating learning technology designers: Guiding and inspiring creators of innovative educational tools (1935). New York, NY: Routledge.

Holden, J. (2013). Playful possibilities for assessment: Fluffy ducks and the queen's gambit. The Scholarship of Teaching, 6(1), 48.

Holden, J. (2016). Good game: On the limitations of puzzles and possibilities for gameful learning. In C. Williams-Pierce (Ed.), Teacher pioneers: Visions from the edge of the map. Pittsburgh, PA: ETC Press.

Holden, J., Kupperman, J., Dorfman, A., Saunders, T., Pratt, A., \& MacKay, P. (2014). Gameful learning as a way of being. International Journal of Learning Technology, 9(2), 181-201.

Holden, J., Stanzler, J., Fahy, M., \& Kupperman, J. (2015). Priorities and pathways for civic caucusing: The Michigan Student Caucus. In Civic media project. Retrieved from http://civicmediaproject.org/works/civic-mediaproject/civiccaucusingmichigan

Hussain, S., \& Al Barwani, T. (2015). Sustainable development at universities in the Sultanate of Oman: The interesting case of Sultan Qaboos University (SQU). In W. Filho (Ed.), Transformative approaches to sustainable development at universities: Working across disciplines (pp. 151-163). New York, NY: Springer International Publishing.

Hwang, G. J., \& Wu, P. H. (2012). Advancements and trends in digital game- based learning research: a review of publications in selected journals from 2001 to 2010. British Journal of Educational Technology, 43(1), E6-E10.

Johri, A. (2011). The socio-materiality of learning practices and implications for the field of learning technology. Research in Learning Technology, 19(3), 207-217.

Kam, M., Agarwal, A., Kumar, A., Lal, S., Mathur, A., Tewari, A., \& Canny, J. (2008, February). Designing e-learning games for rural children in India: a format for balancing learning with fun. In Proceedings of the 7th ACM conference on Designing interactive systems (pp. 58-67). ACM.

Kam, M., Kumar, A., Jain, S., Mathur, A., \& Canny, J. (2009, April). Improving literacy in rural India: Cellphone games in an after-school program. In Information and Communication Technologies and Development (ICTD), 2009 International Conference on (pp. 139-149). IEEE.

Kangas, M. (2010). Creative and playful learning: Learning through game co-creation and games in a playful learning environment. Thinking Skills and Creativity, 5(1), 1-15.

Killham, J., Tyler, S. P., Veneble, A., \& Raider-Roth, M. (2014). Mentoring in an online simulation: shaping pre-service teachers for tomorrow's roles'. Teaching and Learning: The Journal of Natural Inquiry and Reflective Practice, 28(2), 62-79.

Kolko, B. E., \& Putnam, C. (2009, April). Computer games in the developing world: The value of non-instrumental engagement with ICTs, or taking play seriously. In Information and Communication Technologies and Development (ICTD), 2009 International Conference on (pp. 46-55). IEEE.

Kumpulainen, K. \& Sefton-Green, J. (2014). What is connected learning and how to research it? International Journal of Learning and Media, 4(2), 7-18.

Kupperman, J. (2010). DIGW in Kingston, Jamaica. Retrieved from https://www .hastac.org/blogs/jkupp/2010/05/11/digwkingston-jamaica

Kupperman, J., Stanzler, J., Fahy, M., \& Hapgood, S. (2007). The Grasshopper: Games, school, and the benefits of inefficiency. International Journal of Learning, 13(9), 161-168.

Kupperman, J., Robertson, B., \& Baglin, S., (2010). DevInfo GameWorks: Supporting inquiry-based game design. In K. Gomez, L. Lyons, \& J. Radinsky, (Eds.), Learning in the disciplines: Proceedings of the 9th International Conference of the Learning Sciences (ICLS 2010, Vol. 2) (pp. 296-297). Chicago: International Society of the Learning Sciences.

Kupperman, J., Fahy, M., Goodman, F., Hapgood, S., Stanzler, J. \& Weisserman, G. (2011). It matters because it's a game: Serious games and serious players. International Journal of Learning and Media, 2(4), 21-30.

Lave, J. \& Wenger, E. (1991). Situated learning: Legitimate peripheral participation. Cambridge, UK: Cambridge University Press.

Lemke, J., Lecusay, R., Cole, M., \& Michalchik, V. (2015). Documenting and assessing learning in informal and media-rich environments. Cambridge, MA: The MIT Press.

López Turley, R. N., \& Stevens, C. (2015). Lessons from a school district-university research partnership: The Houston Education Research Consortium. Educational Evaluation and Policy Analysis, 37(1S), 6S-15S. 
Moje, E. B., Ciechanowski, K. M., Kramer, K., Ellis, L., Carrillo, R., \& Collazo, T. (2004). Working toward third space in content area literacy: An examination of everyday funds of knowledge and Discourse. Reading Research Quarterly, 39, 38-70.

Pal, J., Pawar, U. S., Brewer, E. A., \& Toyama, K. (2006, May). The case for multi-user design for computer aided learning in developing regions. In Proceedings of the 15th international conference on World Wide Web (pp. 781-789). ACM.

Paley, V. G. (1992). You can't say you can't play. Cambridge, MA: Harvard University Press.

Patra, R., Pal, J., \& Nedevschi, S. (2009). ICTD state of the union: Where have we reached and where are we headed. In Information and Communication Technologies and Development (ICTD), 2009 International Conference on (pp. $357-$ 366). IEEE.

Peppler, K. \& Kafai, Y. B. (2010). Gaming fluencies: Pathways into a participatory culture in a community design studio. International Journal of Learning and Media, 1(4), 1-14.

Resta, P., \& Laferrière, T. (2015). Digital equity and intercultural education. Education and Information Technologies, 20(4), 743-756.

Sachs, W. (2010). Globalization, convergence and the Euro-Atlantic development model. In M. Redclift \& G. Woodgate (Eds.), The international handbook of environmental sociology (2nd Ed.) (pp. 262-275). Northampton, MA: Edward Elgar Publishing.

Salen, K. (2008). (Ed.). The ecology of games: Connecting youth, games, and learning. Cambridge, MA: The MIT Press.

Salen Tekinbas, K. (2014). Learning to pivot: A play on possibility. In S. Walz \& S. Deterding (Eds.), The gameful world: Approaches, issues, applications (pp. 625-628). Cambridge, MA: MIT Press.

Salen, K., \& Zimmerman, E. (2004). Rules of play: Game design fundamentals. Cambridge, MA: MIT press.

Salen Tekinbas, K., Gresalfi, M., Peppler, K., \& Santo, R. (2014). Gaming the system: Designing with Gamestar Mechanic. Cambridge, MA: The MIT Press.

Schmitz, B., Felicia, P., \& Bignami, F. (2015). Acceptance and use of game-based learning in vocational education and training: An international survey. International Journal of Game-Based Learning, 5(4), 50-63.

Sicart, M. (2014). Play matters. Cambridge, MA: The MIT Press.

Slater, M. (1999). Measuring presence: A response to the Witmer and Singer presence questionnaire. Presence: Teleoperators and Virtual Environments, 8(5), 560-565.

Smith, P. (2010). Children at play. West Sussex, United Kingdom: Wiley-Blackwell.

Soja, E. (1996). Third space. Cambridge, MA: Blackwell.

Squire, K. (2010). From information to experience: Place-based augmented reality games as a model for learning in a globally networked society. Teachers College Record, 112(10), 2565-2602.

Squire, K. (2011). Video games and learning: Teaching and participatory culture in the digital age. New York, NY: Teachers College Press.

Steinkuehler, C., Squire, K., \& Barab, S. (Eds.). (2012). Games, learning, and society: Learning and meaning in the digital age. Cambridge, United Kingdom: Cambridge University Press.

Stevens, R., Satwicz, T., \& McCarthy, L. (2008). In-game, in-room, in-world: Reconnecting video game play to the rest of kids' lives. In K. Salen (Ed.), The ecology of games: Connecting youth, games, and learning (pp. 41-66). Cambridge, MA: The MIT Press.

Souto-Manning, M. (2011). Playing with power and privilege: Theatre games in teacher education. Teaching and Teacher Education, 27(6), 997-1007.

United Nations Development Programme (2010). The real wealth of nations: Pathways to human development. New York, NY: Palgrave Macmillan.

Williams-Pierce, C. (2016). Teacher pioneers: Visions from the edge of the map. Pittsburgh, PA: ETC Press.

Wouters, P., \& Oostendorp, H. V. (2013). A meta-analytic review of the role of instructional support in game-based learning. Computers \& Education, 60(1), 412-425.

Young, M. F., Slota, S., Cutter, A. B., Jalette, G., Mullin, G., Lai, B., ... Yukhymenko, M. (2012). Our princess is in another castle: A review of trends in serious gaming for education. Review of Educational Research, 82(1), 61-89.

Zhang, J., Yang, J., Chang, M., \& Chang, T. (2016). Towards a critical understanding of the best practices of ICT in K-12 education in global context. In J. Zhang, J. Yang, M. Chang, \& T. Chang (Eds.), ICT in education in global context (pp. 1-17). Singapore: Springer Singapore. 